\title{
Pessoa vivendo com HIVIAIDS: diagnóstico de uma sentença de morte?
}

\section{People living with HIV / AIDS: diagnosis of a death sentence?}

\author{
Josiane Fernandes Lozigia Carrapato* \\ Marta Helena Meireles de Resende ${ }^{* *}$ \\ Natália Olímpia dos Santos ${ }^{* *}$
}

\begin{abstract}
Resumo: O objetivo geral deste estudo foi identificar como a pessoa vivendo com HIVIAIDS convive com o seu diagnóstico e como isso interfere em sua qualidade e expectativa de vida. A pesquisa de campo realizou-se numa perspectiva qualitativa, envolvendo o Centro de Referência em Moléstias Infecciosas de Bauru e uma amostra de 15 pessoas que estão vivendo com HIVIAIDS. Os instrumentais utilizados foram observação, documentação, entrevista e formulário com perguntas abertas e fechadas. Os resultados apontam que, atualmente receber um diagnóstico positivo para o HIV não representa mais uma sentença de morte, principalmente pela adesão à Terapia Antirretroviral (TARV), que evita o enfraquecimento do sistema imunológico, possibilita a melhora da qualidade de vida do paciente e aumenta a sobrevida, mantendo a doença controlada.
\end{abstract}

Palavras-chave: HIVIAIDS. Inclusão Social. Morte.

\begin{abstract}
The general objective was to identify how a person with HIV / AIDS lives with its diagnosis and how it interferes to the quality and life expectancy. The field research was conducted in a qualitative perspective, involving the people from the Reference Center in Infectious Diseases of Bauru's universe who are in active treatment and a sample of 15 people living with HIV / AIDS. The instruments used were: observation, documentation, interview and form of open and close questions. As a result, it was possible to know that receiving a positive diagnosis of HIV nowadays no longer represents a death sentence, specially because of theadherence to Antiretroviral Treatment (ART) that prevents the weakening of the immune system and allows the improvement of the quality of life of patients and increases survival by keeping the disease under control.
\end{abstract}

Keywords: HIVIAIDS. Social Inclusion. Death

Recebido em: 27/06/2013. Aceito em: 12/09/2014.

\footnotetext{
" Graduada em Serviço Social pela ITE. Especialista em Administração dos Serviços de Saúde Pública e Hospitalar pela UNAERP e Terapeuta de Casal e Família. Mestre em Saúde Coletiva pela Faculdade de Medicina da UNESP de Botucatu. Doutoranda em Saúde Coletiva pela Faculdade de Medicina da UNESP de Botucatu. Docente da graduação do Centro Universitário de Bauru - ITE para o curso de Serviço Social. Docente do curso de pós-graduação da Universidade Sagrado Coração - USC, do Instituto Passo 1 e do Centro Universitário de Bauru - ITE. Assistente Social da Secretaria Municipal de Saúde, atuando no momento, no CRMI - Centro de Referência em Moléstias Infecciosas.
}

* Graduada em Serviço Social pelo Centro Universitário de Bauru em 2012, mantido pela Instituição Toledo de Ensino. 


\section{Introdução}

A Síndrome da Imunodeficiência Adquirida (AIDS) é um grave problema de saúde pública que o Brasil e o mundo vêm enfrentando. Dados do Ministério da Saúde confirmam que, desde o início da epidemia, na década de 1980, até junho de 2012, o Brasil tem 656.701 casos registrados de AIDS, de acordo com o último Boletim Epidemiológico. Em 2011, foram notificados 38.776 casos da doença e a taxa de incidência de AIDS no Brasil foi de 20,2 casos por 100 mil habitantes (OMS, 2012).

Com relação à perspectiva de vida, a ciência ainda não apresenta resposta de erradicação. Porém, na década de 1980 surgiram os medicamentos antirretrovirais para impedir a multiplicação do vírus no organismo. O tratamento é complexo, exige acompanhamento médico para avaliação das adaptações do organismo ao tratamento, seus efeitos colaterais e as possíveis dificuldades em seguir corretamente as recomendações médicas. A epidemia crescente da AIDS no Brasil exige uma busca constante em defesa da vida, o que é possível através da informação, medidas de prevenção e promoção da qualidade de vida.

O Centro de Referência em Moléstias Infecciosas (CRMI) é uma Instituição da área da saúde destinada a toda a população de Baurue dos municípios de abrangênciado Estado de São Paulo, com oferta de três serviços específicos e complementares: Serviço de Assistência Especializada (SAE); Assistência Domiciliar Terapêutica (ADT) e Hospital Dia (HD). As patologias infecciosas atendidas neste serviço são: HIV/ AIDS, Hepatites B e C, Tuberculose, Hanseníase e Doenças Sexualmente Transmissíveis (DSTs).

A AIDS é umas das expressões da questão social que exigem profissionais capacitados para atuar na mediação de situações diversas que surgem cotidianamente. O Serviço Social na instituição CRMI trabalha com as demandas tradicionais e emergentes, sendo estas as que incorporam novas necessidades sociais. AAIDS traz a necessidade de o assistente social ser um profissional dotado de competência, criatividade e eficiência. Para tal é necessário desenvolver o conhecimento científico e assim, a realização de pesquisas, o que viabiliza o conhecimento de novos dados concretos acerca da realidade, oportunizando a consecução de um dos onze princípios do Código de Ética da profissão, que conclama pela qualidade dos serviços prestados à população e com o aprimoramento intelectual, na perspectiva da competência profissional.

O trabalho na área social envolve competência nas dimensões teórico-metodológica, técnico operativa e ético-política, exigindo habilidades como criatividade, versatilidade, iniciativa, liderança, capacidade de negociação interdisciplinar, ou seja, na contemporaneidade o exercício da profissão exige profissionais que negociem com a instituição os seus projetos visando ir além das rotinas institucionais para buscar conhecer $e$ apreender na realidade cotidiana as tendências e possibilidades passíveis de serem apropriadas pelo profissional, desenvolvidas e transformadas em projetos de trabalho. (IAMAMOTO, 2009).

Os objetivos desta pesquisa foram identificar como a pessoa vivendo com HIVIAIDS convive com o seu diagnóstico e como isso interfere em sua qualidade e expectativa de vida, desvelar o papel do Serviço Social no processo de aceitação e entendimento diante do diagnóstico de HIV/ AIDS e investigar os conflitos biopsicossociais da pessoa vivendo com HIVIAIDS.

Para atingir os objetivos propostos, o trabalho foi estruturado de forma a apresentar fundamentação teórica sobre o tema estudado. A partir da introdução, desenvolve-se o contexto histórico do HIVIAIDS, buscando posteriormente fundamentar sua história, adesão ao tratamento e formas de prevenção.

\section{Contexto histórico do HIVIAIDS}

O termo AIDS é um acrônimo de Síndrome da Imunodeficiência Adquirida, seguindo a terminologia em língua inglesa. As primeiras descrições registradas nos países desenvolvidos são de 1981, quando se tornaram conhecidos, em Los Angeles, os casos de cinco adultos do sexo masculino, todos jovens homossexuais, que apresentaram pneumonia e outras infecções. $O$ termo AIDS foi criado no mesmo ano no Centro de Controle de Doenças dos EUA (CDC), para nomear o quadro clínico que estes pacientes apresentavam. (RACHID e SCHECHTER, 2008)

Historicamente o surgimento dessa grave epidemia aconteceu num momento de mudanças sociais e de estilos de vida do final do século $X X$, 
como a urbanização da África, a revolução sexual, os movimentos sociais, a liberação homoafetiva nos EUA e o desenvolvimento de técnicas de coagulação para os hemofílicos (GIMENES, 2002)

Alguns estudos indicam que o Vírus da Imunodeficiência Humana (HIV) entrou em contato com o homem a partir do século XX, quando possivelmente ocorreram mortes isoladas que passaram despercebidas na África. Em uma pesquisa realizada em 1959 sobre determinado tipo de câncer no Zaire, amostras de sangue foram estocadas para estudos futuros, quando novas fórmulas fossem descobertas. Quando surgiram os primeiros casos de AIDS na África as amostras foram testadas, constatando-se que algumas eram positivas (GIMENES, 2002).

Isso indica que o vírus pode ter encontrado as condições ideais para sua disseminação no final dos anos 1970, com as modificações socioeconômicas em países subdesenvolvidos, quando ocorreu a migração das populações rurais. Esse movimento migratório provocou mudanças no estilo de vida das pessoas, como maior liberalização sexual, transfusões de sangue, uso de agulhas contaminadas e a expansão de doenças sexualmente transmissíveis (DSTs) (GIMENES, 2002).

Os primeiros casos de AIDS notificados na América ocorreram no Haiti. Considera-se a possibilidade dos haitianos terem entrado em contato com o HIV na África. Na segunda metade do século $X X$ surgiram as primeiras comunidades homossexuais nos grandes centros urbanos ocidentais. Quando chegou a Nova York e São Francisco, o vírus se disseminou para outras cidades do mundo.

A doença surgiu, primeiramente, entre grupos específicos, mas atualmente se estende a outros grupos inicialmente considerados de menor risco. Como a transmissão é interpessoal, é uma questão universal que não discrimina gênero, classe social, raça ou religião. Isso significa que a doença deixou de ser privilégio de homoafetivos masculinos, hemofílicos e usuários de substâncias psicoativas para ser uma realidade de todos. Na contemporaneidade não há mais grupo de risco, mas é afirmado que toda população encontra-se vulnerável.

Segundo a Organização Mundial da Saúde (OMS), a AIDS é uma doença transmitida pelo vírus do HIV. Esse vírus ataca os leucócitos (gló- bulos brancos), que tem a função de combater microorganismos causadores de doenças. Desta forma, o organismo fica sem defesa e enfraquece conforme o vírus vai se reproduzindo a ponto de contrair determinadas doenças, conhecidas como oportunistas. Ao contrário da maioria das doenças infecciosas, em que a doença se desenvolve poucos dias ou semanas após o contágio, a AIDS pode ficar anos ou mesmo décadas sem se manifestar. A infecção inicial pelo vírus da AIDS é silenciosa, sem qualquer sintoma, por isso o vírus está livre para se espalhar sem ser detectado.

O HIV é transmitido através do contato direto de uma membrana mucosa ou na corrente sanguínea com um fluido corporal que contêm o HIV, tais como sangue, sêmen, secreção vaginal, fluido pré-seminal e leite materno. Os fatores que determinam o tempo de evolução da doença são o tipo de cepa do vírus, carga viral com que a pessoa é contaminada, características genéticas e uso de substâncias psicoativas (SPA). (BRASIL, 2012).

Assim, diante do cenário de enfrentamento de uma doença de grande complexidade, torna-se crucial o aspecto da adesão ao tratamento, que será determinante de como a enfermidade se desenvolverá. A adesão tem estreita relação com a questão da qualidade de vida, sendo um processo dinâmico e multifatorial que inclui aspectos físicos, psicológicos, sociais, culturais e comportamentais, o que implica em ações de corresponsabilização entre a pessoa que vive com HIV, a equipe e toda a rede social envolvida.

\section{Adesão ao tratamento}

Atualmente não há nenhuma cura ou vacina contra a AIDS, embora as pesquisas continuem apresentando progressos. Mas há vários fatores interferentes e cada organismo reage de forma diversa, com variáveis que determinam a evolução da doença, como o tratamento precoce das infecções oportunistas associadas ao HIVIAIDS e a utilização dos antirretrovirais, composto por um coquetel de remédios que reduz a mortalidade e a morbidade da infecção pelo HIV. Os antirretrovirais são fármacos (medicamentos) usados para o tratamento de infecções por retrovírus, principalmente o HIV. A Terapia Antirretroviral (TARV) é altamente eficazna grande maioria dos casos, pois é capaz de reduzir rapidamente a carga 
viral plasmática de pacientes assintomáticos e virgens de tratamento, e aumentar gradualmente as células de defesa denominada CD4 (RACHID; SCHECHTER, 2008).

Portanto, o tratamento adequado pode retardar o curso da doença, determinando uma melhor qualidade de vida. Em contrapartida, a baixa adesão tem como consequência a diminuição da eficácia do tratamento, apiora clínica do paciente e a disseminação de cepas resistentes, reduzindo as opções terapêuticas futuras tanto para os pacientes não aderentes quanto para indivíduos que venham a se infectar com essas cepas resistentes.

Esta realidade impõe aos profissionais, pacientes e cuidadores a missão de buscar estratégias que permitam a introdução de esquemas medicamentosos na rotina de vida do indivíduo, ajudando-o a superar as dificuldades encontradas.

Segundo a OMS, a adesão é o quanto o comportamento de uma pessoa corresponde às recomendações acordadas com o profissional da saúde ao tomar remédios, seguir uma dieta e/ou executar mudanças no estilo de vida. A visão sobre a adesão agrega em sua definição o princípio da autonomia, à medida que se exige a concordância do paciente com as recomendações indicadas, o que implica no papel pró-ativo do mesmo com relação aos cuidados com a própria saúde. A ideia principal desta definição é adesão como resultado do comportamento adotado pelo paciente, pois a aceitação, a motivação e a perseverança de cada um influenciam o seu processo de adesão. O conhecimento sobre a doença, a credibilidade na própria capacidade para aderir e sua participação na definição do esquema terapêutico também são fatores importantes que colaboram para a qualidade da adesão.

Em abordagem sobre este assunto, Caraciolo (2007, p.12) apresenta o seguinte pensamento:

A adesão ao TARV pode ser entendida como o resultado do processo de decisão compartilhada entre o paciente e os profissionais de saúde que o assistem. É fruto do estímulo à autonomia para o autocuidado e do estabelecimento de uma aliança terapêutica permanente, na qual são reconhecidas as responsabilidades específicas de cada um no processo, mas também de todos os que es- tão envolvidos no tratamento. Para atingir o sucesso, a adesão deve ser entendida como uma atividade conjunta na qual o paciente não apenas obedece às orientações médicas, mas as entende, concorda e segue.

A adesão está relacionada a aspectos como estilo e qualidade de vida, ou seja, envolve ações como o protagonismo do sujeito, o vínculo que se estabelece com os profissionais de saúde, a frequência às consultas e a realização dos exames solicitados, os cuidados com a alimentação e higiene, o acesso à informação, o conhecimento e a aceitação da patologia, etc.

É importante que todos os profissionais envolvidos na assistência direta ou indireta estejam mobilizados em torno da adesão, através de um acolhimento que transmita segurança e liberdade para que o paciente possa falar sobre suas dificuldades em relação ao tratamento. $O$ papel dos profissionais neste processo é o de respeitar e apoiar a autonomia, as escolhas e possibilidades das pessoas, participando do processo de corresponsabilização do tratamento (BRASIL, 2008).

Os aspectos relevantes para serem trabalhados na adesão são os efeitos colaterais dos medicamentos, presença de comorbidades como hepatites virais B e C, doenças crônicas, impacto do uso de substâncias psicoativas sobre a adesão, rede de suporte social formada por familiares e amigos, identificação de possíveis lapsos e recaídas no comportamento de não adesão, orientações em casos de dificuldades e estímulo à ajuda mútua entre as pessoas vivendo com HIVIAIDS (CARACIOLO, 2008).

Um dos fatores que interferem na adesão é o aconselhamento pré-teste, uma etapa prévia ao trabalho específico em adesão, quando surge a necessidade de solicitar o teste anti-HIV. Este é o primeiro confronto com uma situação real de risco, constituindo-se em um momento delicado para o paciente, exigindo do profissional a sensibilidade para perceber se este está preparado para a realização do teste, observando seu estado físico e emocional. O profissional deverá avaliar como a pessoa percebe os potenciais riscos e como se sente diante dos possíveis resultados do exame (BRASIL, 2008).

Outra barreira para a adesão é a alteração da autoimagem devido a mudanças corporais 
associadas aos medicamentos, o que afeta a autoestima. A equipe técnica deve considerar as possibilidades de colaborar com a manutenção ou melhora da imagem física do paciente, garantindo o acesso a profissionais e serviços especializados de acordo com cada caso e esclarecendo dúvidas sobre a relação específica entre infecção pelo HIV/AIDS, antirretrovirais e estas mudanças corporais (BRASIL, 2008).

Também é relevante considerar o grau de compreensão e de participação do paciente na condução do tratamento, ou seja, o conhecimento que ele adquire sobre a doença e o tratamento o auxiliam a manter a adesão, o que implica na necessidade de orientações sobre todas as questões, desde a realização dos exames e seus resultados até o objetivo da terapia antirretroviral. É preciso se certificar que as explicações estejam adequadas à sua capacidade de compreensão, pois o paciente tem um conhecimento sobre si mesmo e o mundo que deve ser valorizado. A consideração das fragilidades deve estar aliada à identificação de aspectos da vivência do indivíduo que possam auxiliar no processo de apropriação do tratamento, tais como uma rede consistente de apoio social e familiar, um interesse em novos conhecimentos, planos de futuro e/ou amor à vida.

O surgimento da epidemia da AIDS já ultrapassou três décadas e ainda não foi descoberta a cura, provocando transformações na vida daqueles que vivem e convivem com essa patologia, interferindo em todos os aspectos de suas vidas, especialmente no que se refere a projetos de futuro. Daí a importância de se desenvolver ações preventivas, bem como a consciência sobre a promoção da saúde, o aumento da capacidade das pessoas, dos grupos e da sociedade em geral de se proteger, enfrentando desafios como a falta de informação e outros fatores que vem causando a ramificação da patologia.

\section{Formas de prevenção}

O HIVIAIDS é uma doença que pode ser fatal, causando muito sofrimento, pois a pessoa que vive com o HIV, a partir do diagnóstico, passa a ter que lidar constantemente com a incerteza de futuro, o que inclui a experiência do enlutamento pelas progressivas perdas e pela morte que passa a ser vislumbrada (JANN, 1998). O paciente e seus familiares passam a sentir tristeza pela separação que supõem que acontecerá, como a espera por uma morte que consideram certa. O diagnóstico tem um efeito devastador, pois está ligado à ideia da morte como um fato concreto e iminente. Esta realidade provoca o confronto das pessoas com sua impotência, limitações e mortalidade.

Diante disso, se torna fundamental a prevenção, evitando todas as formas de contágio, sendo que os preservativos masculinos e femininos são a prevenção mais indicada no contato sexual. Devido à importância que a Secretaria Municipal de Saúde, juntamente com o Programa Nacional DST/AIDS atribuem à questão da prevenção, são disponibilizados gratuitamente, em todas as Unidades de Saúde, os preservativos durante $o$ ano todo. A camisinha deve ser utilizada em qualquer tipo de prática sexual, mesmo se o (a) parceiro (a) já estiver com o vírus, pois existe troca de vírus durante a relação sexual.

Outras formas de prevenção a ser consideradas são o descarte de agulhas e seringas após qualquer tipo de procedimento; esterilização de instrumentos cortantes antes do uso, evitando que entrem em contato com o sangue; e nas transfusões de sangue deve haver um rigoroso sistema de testes para detectar a presença do HIV.

Com relação aos usuários de substâncias psicoativas, é necessária a conscientização do risco a que se expõem ao compartilhar seringas e cachimbos, para que realizem medidas de precaução, evitando tal prática. A Política de Redução de Danos é relevante ao abordar a dependência química no aspecto preventivo de doenças infecciosas como o HIV e Hepatites Virais. A Redução de Danos (RD) implica em intervenções singulares, que podem envolver 0 uso protegido, a diminuição do uso da droga, a substituição por substâncias que causem menos agravos ou a abstinência (BRASIL, 2004).

A partir dos anos 80, a RD surge de forma sistematizada em programas de saúde. Inicialmente, objetivando reduzir a contaminação pela hepatite $B$ entre usuários de drogas injetáveis (UDI) e, posteriormente, pela contaminação pelo HIV. No ano de 2004 a RD passa a ser vislumbrada como uma estratégia na Política de Atenção Integral a Usuários de Álcool e outras Drogas, lançada pelo Ministério da Saúde. 
Atualmente, é comum os serviços que proporcionam tratamento às pessoas dependentes de substâncias psicoativas utilizar da estratégia de RD para aqueles que não conseguem realizar o tratamento baseado na abstinência total. A RD é uma estratégia importante na prevenção das Doenças Sexualmente Transmissíveis (DSTs), Hepatite B e C e HIVIAIDS.

Em última análise, é preciso considerar a complexidade de um diagnóstico positivo para HIV e os desafios a ele inerentes. Assim, para a percepção de todos os aspectos envolvidos, é de fundamental importância o conhecimento do impacto psicossocial causado pelas perdas e lutos pelo qual o paciente passa. No caso de doenças crônicas como a AIDS, existem mitos e preconceitos culturalmente enraizados e as perdas podem atingiras várias esferas que envolvem um indivíduo e comprometer sua vida pessoal, afetiva, social, espiritual e profissional.

\section{Aspectos psicossociais e subjetividade}

O momento da entrega do resultado pode despertar sentimentos de morte iminente e medo do futuro, expondo o indivíduo a uma sobrecarga emocional, pois é um momento de incertezas acerca do futuro. As perdas, o luto e a morte estão presentes em todo o processo de adoecimento, relacionando-se não apenas com a morte real, mas também com as mortes simbólicas/ imaginárias.

Em sua abordagem sobre o assunto, Souza (2008, p. 15) pondera que:

Os lutos da AIDS sempre dão uma conotação de morte real, pois mesmo com o aumento da sobrevida, a AIDS é, ainda, frequentemente associada a "doença terminal" e morte. Poucos relacionam esses lutos com as mortes simbólicas que os pacientes enfrentam no processo de adoecimento.

Esses são fatores que interferem na aceitação da doença, na forma como sua gravidade é entendida pelo paciente e na importância que ele dá aos diferentes aspectos que envolvem o tratamento. Absorver um resultado positivo requer tempo e, diante das dificuldades encontradas nesse processo, a negação se torna uma forma de não enfrentar a dura realidade. Uma atitude acolhedora, de saber ouvir, ajudando a pessoa a conhecer seus sentimentos e resgatando ou reforçando seus laços com a vida podem suavizar o momento sombrio vivido.

A revelação do diagnóstico é tarefa que requer cuidado e disponibilidade dos profissionais de saúde, sendo que às vezes se recomenda a intervenção do profissional do campo psicológico. É necessário e urgente que esta revelação ocorra o quanto antes, pois a pessoa deverá iniciar o tratamento de imediato, além de representar um risco de transmissão para outras pessoas devido ao fato de ser uma doença contagiosa.

Saber a verdade é um direito do indivíduo e evita dificuldades para o médico no manejo da situação, pois a pessoa deverá estar consciente da gravidade da doença e se preparar para tratamentos agressivos que poderão trazer efeitos colaterais desagradáveis.

Os aspectos biopsicossociais da pessoa que descobre que está com o HIVIAIDS podem interferir na adesão. Neste momento, surgem quadros de angústia, depressão, uso abusivo de álcool ou outras substâncias psicoativas. Transtornos psiquiátricos preexistentes ao conhecimento do diagnóstico do HIVIAIDS podem ser agravados a partir do diagnóstico ou surgir em decorrência de comprometimentos físicos da doença ou tratamento.

Fernandes (1990, p.15) afirma sobre isto o seguinte:

O impacto vai além das estatísticas sanitárias. A AIDS envolve ampla associação de sexo, morte, sangue e drogas, invocando medos e inibições básicas da espécie humana. Provocando amplo questionamento nas relações humanas, no amor e na sexualidade.

Neste momento tão delicado na vida do sujeito é importante saber ouvir com atenção a mensagem que ele transmite para compreender qual o significado que a doença adquire em sua vida. O profissional de saúde deverá auxiliar as pessoas a lidar com perdas objetivas, tais como parceiro, emprego, imagem corporal, saúde, autonomia e também subjetivas como sonhos e projetos, em decorrência do HIVIAIDS.

Outro fator que pode interferir nos aspectos psicossociais refere-se à revelação do diagnóstico a terceiros, pois muitas vezes o medo do preconceito e da discriminação que o estigma da doença traz podem ser fatores para a não

326 Emancipação, Ponta Grossa, 14(2): 321-336, 2014. Disponível em <http://www.revistas2.uepg.br/index.php/emancipacao> 
aceitação do diagnóstico e, consequentemente, a não adesão ao tratamento. A fragilidade da saúde exige cuidados específicos em todos os níveis de atenção à saúde, fazendo-se necessário que haja alguém não somente com quem compartilhar o diagnóstico como também para servir de suporte para as necessidades que o tratamento requer.

AAIDS/HIV em seu desenvolvimento epidemiológico apresenta três fases, sendo a primeira denominada Epidemia da Infecção por HIV, a segunda Epidemia da AIDS e a terceira Epidemia das respostas sociais, culturais, econômicas e políticas à AIDS. É nessa última que ocorre o que denominamos de estigma, preconceito e discriminação (MANN,1987).

A estigmatização e discriminação são processos sociais em constante mutação, no entanto, ainda nos dias de hoje a pessoa vivendo com HIVIAIDS é considerada diferente, excluída socialmente e com sofrimento excessivo por adquirir a doença. $O$ estigma e a discriminação geram a desigualdade social, ou seja, são fenômenos sociais e culturais ligados às ações de grupos inteiros de pessoas, e não consequências de comportamento individual (PARKER e AGGLETON, 2001).

O paciente poderá depender de cuidados básicos de familiares e amigos com quem convive e que desenvolvem papel importante em sua vida, constituindo-se em um apoio crucial para o sucesso do tratamento. No entanto, é necessário compreender que apenas o indivíduo conhece sua dinâmica familiar e pode prever a reação das pessoas próximas com quem se relaciona. A realidade de ter um de seus membros diagnosticado com uma doença considerada letal e que revela segredos como a homossexualidade ou o uso de substâncias psicoativas pode causar um grande abalo na estrutura familiar, o que gera medo, discriminação, preconceito e até rejeição. Ser uma pessoa que adquiriu o HIVIAIDS pressupõe a falta de integridade moral, expondo a vida particular, a sexualidade e a intimidade das pessoas.

A pessoa vivendo e convivendo com HIV/ AIDS temque elaborar todos os seus sentimentos e a vergonha de ser portadora de uma doença que denuncia, além do diagnóstico, o seu estilo de vida, trazendo a público o que se passa na esfera do privado.
Nos aspectos psicossociais, a qualidade das ações depende de um trabalho em equipe interdisciplinar, onde os casos devem ser discutidos com responsabilidade e encaminhados no próprio serviço a outros profissionais como psicólogos, enfermeiros, nutricionistas, entre outros.

É nesse cenário que o assistente social realiza suas intervenções, buscando estratégias de acolhimento para início do vínculo efetivo entre profissional de saúde e pessoa vivendo com HIV/ AIDS. As ações do assistente social são a busca de democratização do acesso às unidades e aos serviços de saúde, atendimento humanizado, estratégias de interação da instituição de saúde com a realidade, interdisciplinaridade e estímulo à participação cidadã.

\section{A AIDS e o Serviço Social}

A pessoa vivendo com HIVI AIDS necessita de cuidados específicos em todos os níveis de atenção à saúde e busca apoio nos profissionais com os quais passa a ter uma relação mais estreita e contínua.

Neste sentido, o Serviço Social deve atuar na equipe de saúde com a finalidade de compreender os aspectos sociais, econômicos e culturais que influenciam no processo saúde e doença, buscando alternativas e estratégias para o enfrentamento desses aspectos. Assim, o ser humano é visto em totalidade, com suas necessidades materiais, sociais e emocionais.

O Serviço Social tem o seu foco na população excluída, e no caso das pessoas vivendo com HIVIAIDS, o aspecto da exclusão é ainda mais acentuado, não apenas pela questão socioeconômica, mas pela discriminação sofrida em relação à família e à sociedade. $\mathrm{O}$ foco do trabalho social, portanto, está inserido em ações de caráter preventivo educativo, assistencial e de apoio psicossocial.

O processo educativo envolve a desmistificação da doença, formas de prevenção, redução do preconceito, enfatizando a solidariedade e os direitos do indivíduo e procurando minimizar seus conflitos. As ações de caráter assistencial referem-se ao suporte material que viabilize a prevenção e o tratamento através de recursos institucionais e da comunidade. Em nível de apoio psicossocial, a atenção volta-se essencialmente 
aos aspectos emocionais do paciente e de sua família.

O profissional irá se deparar com questões como a angústia da morte, dor, perda, sentimentos de hostilidade, rupturas com antigos padrões de vida, raiva, culpa, discriminação, medo, isolamento, solidão, quando se faz necessária uma atuação voltada principalmente para o indivíduo, que passa a enfrentar os desafios de lidar com a doença e continuar a sobreviver (GIMENES, 2002).

A dinâmica familiar deve ser considerada em todo o processo do tratamento por representar uma estrutura de apoio importante para o indivíduo. A aceitação, o carinho e o amor da família representam conforto e incentivo para o paciente realizar o tratamento. É fundamental que a sociedade e, consequentemente, a família, se abra para a solidariedade e o respeito aos sentimentos do paciente, que pode e deve ter uma convivência social e familiar normal, cercada de parentes, familiares e amigos.

\section{Metodologia}

Reconhecendo as várias determinações do processo saúde-doença e procurando ver o ser humano em sua totalidade, com suas necessidades materiais, sociais e emocionais, foi realizada a tipologia da pesquisa quali-quantitativa e descritiva com levantamento bibliográfico e de campo. A pesquisa bibliográfica serviu para a construção do referencial teórico, utilizando-se de fontes como livros, revistas especializadas, legislação e dicionários, sendo a mesma realizada entre os meses de fevereiro e abril. A pesquisa de campo foi realizada através de um contato direto com os sujeitos nos meses de julho e agosto de 2012.

Ressalta-se, ainda, que a tipologia da pesquisa foi descritiva. Os instrumentos de coleta de dados utilizados foram entrevista por meio de formulário, com perguntas abertas e fechadas e observação sistemática, envolvendo pessoas vivendo e convivendo com HIVIAIDS e que são pacientes do CRMI.

O projeto foi aprovado pelo Comitê de Ética em Pesquisa da Secretaria Municipal de Saúde de Bauru, sob o protocolo n 34491/2012.

As entrevistas possibilitaram a compreensão da realidade dos entrevistados com perguntas que permitiram colher os dados significativos atribuídos aos fatos pelos sujeitos e, de forma específica, sua visão sobre o diagnóstico e as perspectivas de futuro.

Para a identificação dos entrevistados foi atribuída a caracterização de sujeitos, que foram numerados a fim se preservar sua identidade.

O formulário visou atender aos objetivos da pesquisa, tanto o geral quanto os específicos. De acordo com a autorização dos usuários, os dados coletados foram registrados manualmente e gravados para serem posteriormente transcritos.

A pesquisa de campo envolveu todo o universo do CRMI que estão ativos no tratamento, ou seja, estão cadastrados no Sistema Nacional de Cadastramento Logístico de Medicamentos (SICLOM), totalizando aproximadamente 1000 pacientes.

A coleta se deu por amostra não probabilística intencional. Por ser uma pesquisa qualitativa, a população entrevistada foi constituída de15 pessoas vivendo com HIVIAIDS, denominado na análise como PVHA - pessoa vivendo com HIV/ AIDS, todos adultos e de ambos os gêneros. Os critérios utilizados para seleção dos sujeitos da pesquisa foram ter o diagnóstico de HIVIAIDS e estar ativos no tratamento, sem qualquer outra exigência ou condição. Os entrevistados foram escolhidos de acordo com sua disponibilidade de tempo, muitas vezes em intervalos de consultas e exames, sendo que algumas entrevistas foram agendadas por telefone, ocasião em que foram realizadas visitas domiciliares. Desta forma, o local das entrevistas foi uma sala de atendimento do CRMI e a residência de alguns pacientes, incluindo uma Casa de Apoio mantida pela Sociedade de Apoio à Pessoa com Aids de Bauru (SAPAB). As entrevistas realizadas nas residências permitiram observar a dinâmica familiar e a realidade vivida pelos entrevistados.

O pré-teste foi realizado em forma de diálogo, entrevista e formulário, sendo aplicado em 02 sujeitos. O objetivo do mesmo foi tomar uma subamostra através da entrevista por meio do formulário elaborado para analisar as questões quanto à sua adequação no processo de coleta de dados, bem como se apresentava como elementos fundamentais a fidedignidade, a validade e a operatividade, evidenciando possíveis falhas antes de sua aplicação no restante do universo.

Após a coleta de dados, estes foram categorizados de modo a permitir sua análise e interpretação, processos intimamente relacionados. A análise objetiva organizar e

328 Emancipação, Ponta Grossa, 14(2): 321-336, 2014. Disponível em <http://www.revistas2.uepg.br/index.php/emancipacao> 
sumariar os dados para que forneçam respostas ao problema proposto e a interpretação objetiva procurar o sentido mais amplo das respostas. Foi realizada a tabulação por categorização e em seguida a análise dos dados empíricos, dividindoos em três eixos:

- Questões relativas ao diagnóstico;

- Questões relacionadas ao aspecto psicossocial;

- Questões relacionadas à saúde.

Ressalta-se que todo o processo foi realizado dentro dos parâmetros éticos, pautando-se no Código de Ética do assistente social,que permeia toda a conduta profissional, especialmente amparando-se no princípio que aborda o empenho na eliminação de todas as formas de preconceito, incentivando o respeito à diversidade,à participação de grupos socialmente discriminado se à discussão das diferenças. A ética pressupõe uma sociedade mais justa, onde a dignidade de todos seja respeitada com base na observância de procedimentos que respeitem os valores morais e culturais dos indivíduos.

$\mathrm{Na}$ área da saúde, o respeito humaniza o atendimento ao usuário, na medida em que este é considerado em sua singularidade e são criadas condições para que tenha maiores possibilidades para exercer sua vontade de forma autônoma. Respeito, responsabilidade, solidariedade e empatia são algumas atitudes com potencial de tornar o cuidado mais humano e efetivo.

\section{RESULTADOS}

\section{Impacto da descoberta do diagnóstico - enfrentando o preconceito e a discriminação}

Tempo de diagnóstico HIVIAIDS

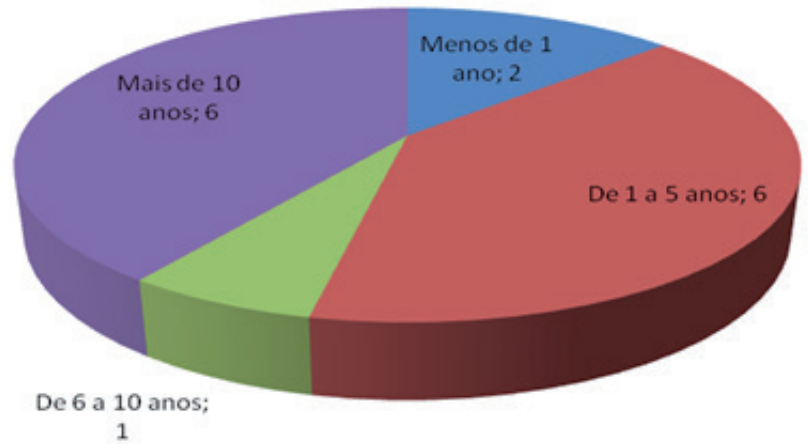

Fonte: Carrapato, Resende e Santos, 2012.
Analisando o tempo de contaminação, verifica-se que seis dos entrevistados conhecem sua condição de soropositivo há mais de dez anos, outros seis a conhecem entre um a cinco anos, conforme gráfico acima. O número de portadores que conhecem sua soro conversão há menos de um ano é de duas pessoas e apenas uma pessoa convive com a notícia da soropositividade há sete anos. Deste total, um indivíduo relata ainda não ter desenvolvido a doença, o que pode levar mais de dez anos para acontecer, fator que depende de cada organismo.

\section{Sentimento no início da descoberta}

Para os sujeitos entrevistados, o sentimento que surgiu no momento em que receberam o diagnóstico foi tristeza pelo desconhecimento, seguido do medo de não suportar o Tratamento Antirretroviral - TARV, e em terceiro lugar surgiu à aceitação.

Outros sentimentos apontados foram ainda culpa por comportamento de risco, medo do preconceito, raiva, etc, conforme a fala seguinte:

\begin{abstract}
"Foi medo não de ter sido contaminado, medo de ter contaminado minha ex-mulher e minha filha. Eu não contraí por causa de homossexualismo, infelizmente foi negócio de mulher minha ex-mulher me odeia porque ela achou que eu podia ter contaminado ela e a minha fiIha [...] eu fui inconsequente, acredito que este castigo foi merecido, eu aprendi muita coisa, tudo vem com um propósito, eu podia ter me prevenido" (PVHA 1, masculino, 40 anos)
\end{abstract}

Esta fala confirma a colocação de Lima (2003) sobre a AIDS estar mais associada a comportamentos pecaminosos do que outras enfermidades e, consequentemente, a doença ser percebida pelos pacientes como uma punição pelos seus atos imorais. Em tempos mais remotos, a doença e a saúde estavam relacionadas a convicções religiosas, quando a doença era compreendida como uma punição divina devido à violação de normas religiosas e morais. $\mathrm{O}$ paciente, quando se considera merecedor do castigo, demonstra que estas convicções ainda estão presentes nos dias atuais.

"Quando eu descobri foi tudo junto, revolta, medo, insegurança, foi um choque, tive tristeza pelo desconhecimento, eu e o meu marido 
tínhamos medo de não suportar o tratamento e morrer. Chorávamos juntos" (PVHA 5, feminino, 44 anos).

"Bom, no meu caso seria uma culpa por eu saber da pessoa que era soropositiva. Quando eu descobri foi um choque pra mim. Foi uma atitude assim que eu pensei que na primeira vez não pega. Pegou" (PVHA 3, feminino, 44 anos).

"Eu não senti medo por mim, eu senti medo pelas pessoas que estão ao meu redor, eu não sabia qual seria a reação delas, como elas iam me ver, a maioria das pessoas que me cercam, filhos, família e amigos, eles me veem como uma pessoa perfeita. [...] Acho que essa minha aceitação tem mais é isso, porque eu não quero transformar o HIV na minha vida como uma coisa letal e eu tenho medo de que as pessoas transformem isso, porque muitas já se afastaram" (PVHA 8, feminino, 43 anos).

Estes são sentimentos a serem enfrentados com coragem, determinação e ações eficazes. Essas pessoas se deparam com uma realidade que provoca diferentes reações, pois segundo Ferreira (2003, p.40): "O diagnóstico do HIV é, sem dúvida, muito ameaçador, uma vez que a ciência e os cientistas não possuem instrumentos apropriados para seu combate".

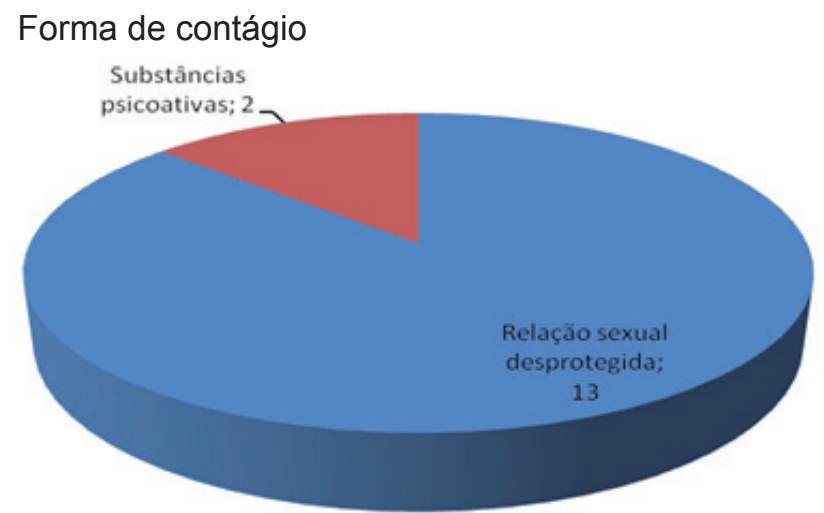

Fonte: Carrapato, Resende e Santos, 2012.

Quanto à forma de transmissão, 13 dos entrevistados referem ter adquirido o vírus através de relação sexual desprotegida, enquanto 2 pessoas afirmam tê-lo adquirido através do uso de substâncias psicoativas.

Estes dados mostram a dificuldade existente para que as pessoas compreendam a importân- cia da prevenção através do uso de preservativos. Os homens manifestam preconceito em participar de entidades sociais que atendem portadores do vírus HIV no que se refere à prevenção e as recontaminações do vírus HIV através de relações sexuais, sendo estas na maioria das vezes controladas por eles, cabendo-Ihes aceitar ou não o uso do preservativo. Barker (2008) pondera que os homens em geral procuram menos ajuda do que as mulheres, o que aumenta as chances de se contrair o HIV, demonstrando a necessidade de trabalhar com os mesmos para mudar suas atitudes e comportamentos.

\section{Sentimento após iniciar o tratamento}

Após iniciar o tratamento contra o HIV/ AIDS, os sentimentos continuaram contraditórios, mas a aceitação passou a ser o sentimento mais referido pelos entrevistados.

Kübler-Ross (1994) avaliou o impacto psicológico de doenças terminais, acompanhando pacientes nos anos 60 e observou que os mesmos passam por cinco estágios do diagnóstico até a proximidade da morte: negação, raiva, barganha, depressão e aceitação. Este último estágio foi confirmado pelos dados. A maioria das pessoas afirma que o sentimento de aceitação foi construído com o passar do tempo e com o início do tratamento, quando o paciente passa a conhecer mais o mesmo. Este é o momento em que, segundo a autora, desaparece a depressão e a raiva quanto ao seu destino e surge a luta pela vida:

Ainda continuo na culpa, e hoje a minha cabeça está mais aberta para a aceitação, hoje eu trabalho no meio dessas pessoas que são soropositivas e tenho outro conceito sobre a doença. [...] Eu trabalho normalmente, não sinto dor nenhuma, porque ela não dói, é uma doença silenciosa. Estou aprendendo a cada dia a conviver com o HIV (PVHA 3, feminino, 44 anos).

Venho aperfeiçoando. Fico sempre procurando saber das pesquisas, onde é que eles estão, se já descobriram a cura dela" (PVHA 14, masculino, 55 anos).

Os estágios são enfrentados de forma diferente para cada pessoa. Para alguns os sentimentos são mais ou menos intensos e as per- 
das também são percebidas de forma diferente. Ocorrem as perdas reais, objetivas, como a morte de pessoas próximas ou do parceiro, a perda do emprego, da autonomia, da saúde, mas também perdas no estado psicossocial, subjetivas, que se referem aos sonhos, projetos e ao desejo de imortalidade.

\section{Preconceito}

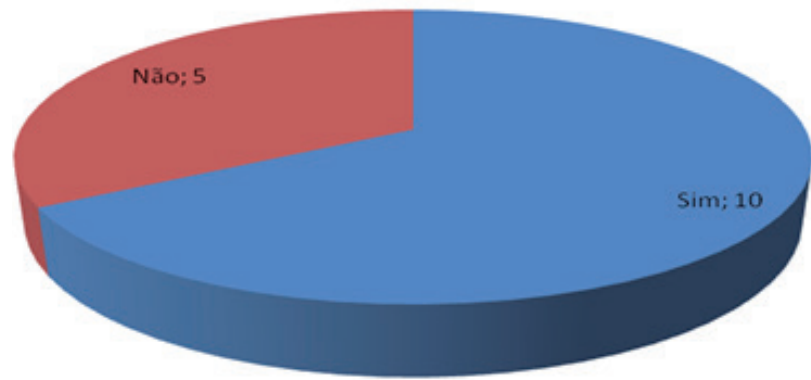

Fonte: Carrapato, Resende e Santos (2012).

Quanto ao preconceito, dez dos entrevistados afirmam que já o sofreram e cinco referem nunca ter sofrido nenhuma forma de preconceito em decorrência de seu diagnóstico.

Percebe-se que algumas pessoas guardam segredo sobre a soropositividade pelo medo do preconceito, que acontece na esfera social, no ambiente de trabalho e até mesmo dentro da família. Conforme Ferreira (2003), muitos pacientes não temem a morte em si, mas o processo de morrer em função não das penas ao corpo impostas pela doença orgânica, mas pela dor do preconceito e discriminação decorrente da patologia social.

Os entrevistados relatam perceber o preconceito dos próprios médicos, o afastamento dos amigos, na família, entre outros:

Com os próprios médicos a gente já acha que tem preconceito, eles mantém distância. E a minha mãe é totalmente preconceituosa. Não é só comigo não, é com qualquer pessoa [...] Tem muitas pessoas que tem preconceito, mas não se abrem. Mas a gente percebe quando tem (PVHA 14, masculino, 55 anos)

Com minha mãe, não foi direto, mas ela separava o copo de água que eu bebia, uma vez ela bateu com o portão na minha cara (PVHA 1 , masculino, 40 anos)

Minha mãe foi a primeira a contar pra todo mundo (PVHA 13,masculino, 38 anos)
Mesmo com toda a legislação favorável, dentre os entrevistados, quatro pessoas referem ter perdido o emprego em decorrência do preconceito, conforme as falas seguintes:

Eu era cabeleireiro e fui mandado embora do emprego porque mexia com material cortante, a tesoura (PVHA 13, masculino, 38 anos)

Eu fui mandada embora do serviço porque a minha patroa achou que eu estava pondo em risco a vida dos seus filhos (PVHA 07, feminino, 45 anos)

É importante destacar que a Declaração dos Direitos Fundamentais da Pessoa Portadora do Vírus HIVIAIDS, entre outros itens, preconiza que toda ação que tende a recusar aos portadores do vírus um emprego, um alojamento, uma assistência ou privá-los disso deve ser considerada discriminatória e punida por lei (BRASIL, 1989).

\section{O impacto da AIDS numa visão psicossocial}

Evidencia-se na pesquisa que a maioria dos sujeitos entrevistados vive bem com seu diagnóstico, com naturalidade, e que aprenderam a conviver com a doença. Isso se deve aos avanços do tratamento, com a percepção de que a adesão permite maior qualidade de vida.

Eu tive que aprender a conviver. Cada dia para mim é um dia que eu aprendo mais, porque cada dia a gente tá de um jeito (PVHA 13, masculino, 38 anos).

Tirando o medo e a incerteza do amanhã eu convivo bem, [..] não pode dar importância acima daquilo que a coisa merece, aí vira paranoia (PVHA 8, feminino, 43 anos).

Com relação aos conflitos biopsicossociais vividos em decorrência do diagnóstico de HIV/ AIDS, a maioria relata ter uma vida normal, muitas vezes nem se lembrando de que tem esta doença. Mas houve revelação de temores, como se observa na seguinte fala:

Foi o caso daquele rapaz que eu fiquei com ele. O problema que ele faleceu eu não sabia se pegava assim. Hoje me sinto com medo de tudo, da forma que ele morreu, do jeito que eu ia vê-lo no hospital, ver ele entubado daquele jeito. [...] Tenho medo daquela doença que ele morreu, de eu estar internada igual ele, ficar entubada (PVHA 3, feminino, 44 anos). 
No caso acima citado, trata-se de um homoafetivo masculino, que adota um nome feminino e se identifica como tal, e que perdeu o parceiro devido a complicações em decorrência de seu diagnóstico. Hendrick (2006) aponta alguns fatores relacionados à AIDS que se referem ao luto como estigma social proveniente da discriminação que dificulta a formação e manutenção da rede de apoio, e no caso de relações homossexuais, quando morre o parceiro, o luto não é reconhecido socialmente e não é permitido participar dos rituais de despedida. A pessoa que sobrevive à AIDS, além de conviver com o estigma da doença, não tem com quem compartilhar sua dor, porque ela não foi autorizada pela sociedade.

\section{HIVIAIDS com relação à qualidade $e$ expectativa de vida}

AAIDS provoca grandes transformações na vida daqueles que convivem com ela, nos sentidos físico, psíquico, social e espiritual, interferindo nas relações sociais, na vida profissional e afetiva, na sexualidade, na vida reprodutiva, afetando os projetos de vida do indivíduo (SOUZA, 2008).

Muitas vezes a afetividade e a neutralidade das pessoas é atingida, e essa nova situação acaba colocando um filtro nas relações, fazendo com que ocorra o distanciamento de algumas pessoas, enquanto são mantidas apenas as amizades mais profundas que demonstram ser resistentes ao preconceito.

Impacto do diagnóstico na qualidade e expectativa de vida

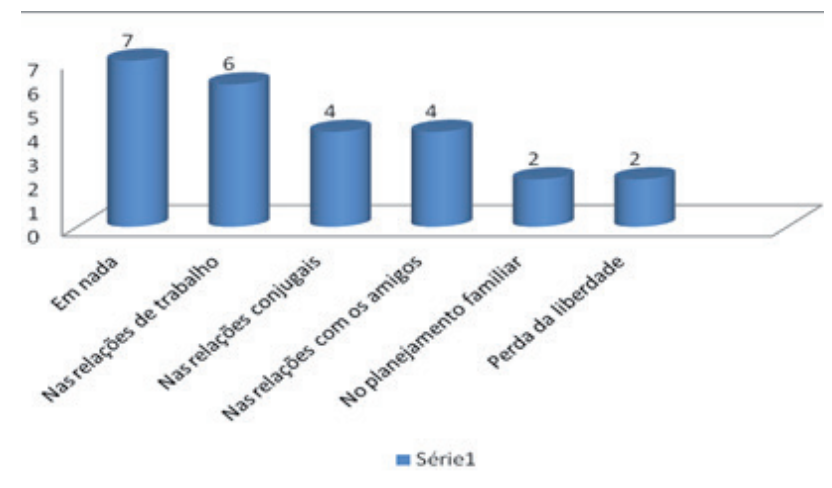

Fonte: Carrapato, Resende e Santos (2012).

Embora sete dos entrevistados afirmem que o diagnóstico positivo não tenha afetado em nada suas vidas, seis pessoas relatam ter sido afetadas nas relações de trabalho, quatro nas relações com os amigos e conjugais, duas referem que o diagnóstico interferiu no planejamento familiar e/ou nas relações familiares e outras duas na perda da liberdade. Este último item se refere a hábitos como tomar bebidas alcoólicas ou viajar, que foram comprometidos com o tratamento. Observa-se que existe uma associação de fatores que afetam a vida das pessoas.

Eu não posso trabalhar mais, metade dos amigos se afastaram. E eu queria ter mais um filho e o médico disse que por enquanto eu não posso ter. Eu acho que interferiu mesmo. No começo, minha irmã tinha preconceito de mim. Minha mãe também se afastou de mim. [...] Dá para ver que ela tem preconceito. A gente guarda isso (PVHA 12, feminino, 30 anos).

Eu não tenho interesse por ninguém mais, eu que me afastei (PVHA 13, masculino, 38 anos)

Todas as perdas sofridas após o diagnóstico positivo, e ainda o preconceito e a discriminação que o indivíduo passa a enfrentar, representam uma espécie de morte social que, segundo Fonseca (2004, p. 117) "representa a morte simbólica de um indivíduo perante os grupos dos quais participa. Socialmente, o mundo do doente começa a reduzir-se". É como se, a partir do momento em que se descobre que a pessoa está contaminada, ela deixasse de existir para a sociedade. Esta concepção deixa o indivíduo excluído e entregue à solidão.

\section{Adesão à Terapia Antirretroviral}

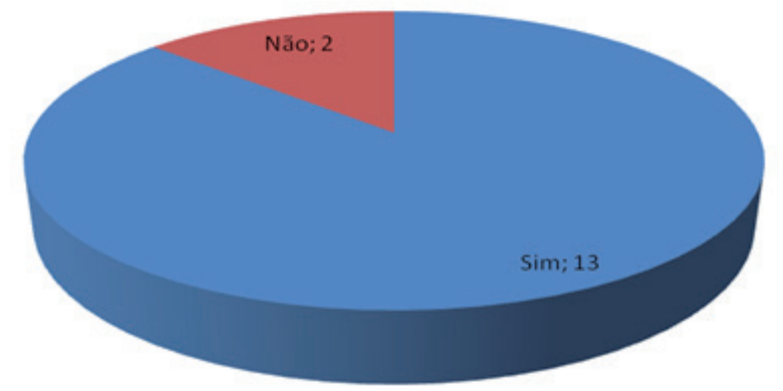

Fonte: Carrapato, Resende e Santos (2012).

A terapia antirretroviral combinada (TARV) produziu um grande impacto na epidemia de HIV/ 
AIDS, possibilitando a diminuição da morbimortalidade e da ocorrência de infecções oportunistas, o aumento da sobrevida e a melhoria da qualidade de vida de seus portadores. A adesão foi aferida por 13 dos entrevistados, que relatam comprometimento com o tratamento. Duas pessoas não possuem adesão, uma delas por não ter conseguido incorporá-la à sua rotina e a outra porque possui o vírus do HIV, mas até o momento ainda não desenvolveu a AIDS. De modo geral, a adesão é considerada importante pelos pesquisados, como se verifica na fala seguinte:

Com o tratamento eu tenho um ritmo de vida normal. Minha carga viral está indetectável e a defesa do organismo mais alta. Se eu não fizesse o tratamento, ia ficar procurando minha própria destruição. Inclusive na época que eu fiquei sabendo que tinha o vírus, teve outro colega meu que ficou sabendo no mesmo dia. Uns 3 meses depois ele morreu. Se entregou (PVHA 14, masculino, 55 anos).

No momento em que ocorre a confirmação do diagnóstico de HIV, é comum que os pacientes fiquem inseguros quanto ao desenvolvimento da doença, ao tratamento e ao medo do estigma, o que faz com que muitas vezes o paciente se sinta extremamente vulnerável. Souza (2008, p.69) destaca que a equipe de saúde deve cuidar da "alma" do paciente, por meio da escuta e do acolhimento de sua dor, auxiliando-o a vivenciar e elaborar todas as etapas dos vários processos de luto que enfrenta na trajetória da doença.

É importante que a PVHA se sinta acolhida pela equipe de saúde, dentre eles o profissional do Serviço Social, que irá acompanhar seu tratamento. Para tal acolhimento é necessário que seus medos sejam ouvidos e suas dúvidas esclarecidas, através da efetivação dos princípios de autonomia do sujeito nas decisões que envolvam a sua vida.

\section{Relação com o Serviço Social}

Quando questionados quanto ao papel do Serviço social no processo de aceitação e entendimento diante do diagnóstico de HIVIAIDS, constata-se que nem todos tiveram contato com o mesmo no momento do diagnóstico, tendo sido informados da doença por outros profissionais de saúde, como o médico infectologista. Informar o diagnóstico não está entre as competências do assistente social, mas sim prestar apoio social.

Mas todos os entrevistados afirmam que atualmente são auxiliados pelo profissional de Serviço Social, que presta orientações quanto a direitos e benefícios previdenciários a fim de garantir o acesso aos recursos disponíveis de acordo com a legislação vigente. O papel desempenhado pelo profissional se constitui em importante fonte de apoio no tratamento e nas relações sociais dos pacientes como protagonistas de sua história, através de práticas que visam a sua autonomia, sempre de acordo com as demandas trazidas cotidianamente.

Ajudou no começo e vem contribuindo com benefícios, remédios e tratamento. Percebo que o Serviço Social está contribuindo para a minha qualidade de vida (PVHA 5, feminino, 44 anos).

No começo ajudaram bastante, acudiram até com cesta básica, me ajudou com o pedido de benefício do INSS, eu sempre fui ajudado. No caso o benefício de invalidez, fui bem orientado [...] Se precisar de orientação tem com certeza (PVHA 14, masculino, 55 anos).

O Serviço Social tem como objetivo principal a inclusão social, comunitária e familiar para combater o preconceito e a discriminação dos pacientes que sofrem de moléstias infecciosas e sensibilizar usuários e familiares quanto à adesão ao tratamento proposto pela equipe de saúde, bem como intervir junto aos casos que apresentem dificuldades em dar continuidade ao tratamento.

O assistente social elabora o diagnóstico social no primeiro atendimento, visando conhecer detalhadamente as expressões da questão social como a família, o contexto de trabalho, diagnóstico e tratamento, história de vida, aspectos culturais, sociais e econômicos. Nesse atendimento individual é iniciado o vínculo que permeará os demais atendimentos, sendo de extrema importância para romper gradualmente com o preconceito e possibilitar reflexões que contribuirão com a adesão ao tratamento e inclusão familiar e social.

Quando necessário, será realizado contato telefônico com familiares e agendado atendimento do paciente com sua respectiva família para transmitir informações sobre o HIVIAIDS, 
objetivando minimizar o comportamento discriminatório da família.

O Serviço Social do CRMI criou um grupo terapêutico semanal aos pacientes excluídos da família, da sociedade ou de si próprio. Alguns dos entrevistados participam do grupo e foram convidados a participar das entrevistas, de acordo com sua disponibilidade e aceitação. $O$ grupo possibilita ao paciente o apoio necessário para trabalhar os sentimentos de exclusão, bem como orientações sobre direitos previdenciários, civis e sociais. O paciente com dificuldades de aceitação da doença e do tratamento também é encaminhado pela equipe para participar desse grupo denominado "Grupo Qualidade de Vida”.

\section{Considerações finais}

AAIDS surgiu no início da década de 1980 e vem se constituindo desde então em um dos mais sérios problemas de saúde pública, uma vez que permanece sem cura e provoca grandes mudanças na vida daqueles que convivem com ela.

Com relação ao momento da descoberta do diagnóstico, os sentimentos que surgem são de tristeza pelo desconhecimento e de medo de não suportar o TARV, sentimentos intensificados por se tratar de uma doença socialmente estigmatizada e envolta em mitos e preconceitos.

Após iniciar o tratamento e conhecer mais sobre o mesmo, o sentimento que se desenvolve é o de aceitação, que se deve à superação de outros sentimentos como raiva, medo do tratamento, tristeza pelo desconhecimento e culpa. Esta aceitação está relacionada ao tempo de diagnóstico, pois os pacientes passam a ter maior conhecimento sobre a doença.

Quanto ao preconceito, embora muitas vezes dissimulado, ele é percebido na família, na sociedade, no ambiente de trabalho e até mesmo por parte dos médicos. Muitas vezes está vinculado à falta de informação sobre as formas de transmissão, bem como a antigas concepções que associam a doença à promiscuidade e à crença de que ela poderia ter sido evitada. $\mathrm{O}$ diagnóstico revela segredos que expõem a vida particular das pessoas, colocando em dúvida sua integridade moral. Embora haja uma legislação específica que protege esta população, o preconceito foi o responsável pela perda do emprego por quatro pessoas que participaram da pesquisa.

Quanto à dimensão psicossocial, a maior parte revela que aprendeu a viver e conviver bem com seu diagnóstico, o que se deve aos avanços do tratamento, uma vez que a adesão ao TARV permite uma vida com mais qualidade. Mas surgem depoimentos de pessoas que vivem conflitos causados por fatores como a morte de pessoas próximas com a mesma doença, mudanças de hábitos, perda do emprego, da autonomia e também pelo fato de adquirir a doença através de parceiro que era depositário de sua confiança.

A maioria dos entrevistados afirma não ter sido afetada em sua qualidade e expectativa de vida, mas a linguagem não verbal deixa transparecer que de alguma forma sua vida foi transformada, pois tiveram que se adaptar a uma nova fase de atenção constante à saúde. Uma parcela menor menciona mudanças nas relações de trabalho, conjugais, nas amizades, no planejamento familiar e na perda da liberdade que usufruíam antes do diagnóstico.

Para que o tratamento tenha sucesso, espera-se das instituições voltadas a esses pacientes que ofereçam um atendimento de qualidade, que preserve sua dignidade humana. Quanto a esse aspecto, o assistente social exerce papel fundamental em todo o processo de entendimento do diagnóstico de HIVIAIDS, prestando orientações sobre temas diversos ao paciente. Todos afirmam que após receber o diagnóstico e entendê-lo, o Serviço Social tem sido de grande importância, pois se sentem acolhidos em suas necessidades.

Após a análise das informações geradas pelas entrevistas e pelos estudos realizados, foi possível constatar que a evolução da doença depende de variáveis individuais. Cada pessoa irá encarar a doença de uma forma diferente e a enfrentará de maneiras diversas, conforme a elaboração que fizer desta nova realidade.

$\mathrm{O}$ aspecto mais importante no enfrentamento da doença está na adesão ao TARV, pois os medicamentos atuam na redução da carga viral e na melhora do sistema imunológico. A adesão constitui-se em um desafio que envolve amplos fatores, não apenas objetivos, mas também subjetivos, com questões que dependem do grau de envolvimento do paciente. Fatores como o estilo e a qualidade de vida, a frequência às

334 Emancipação, Ponta Grossa, 14(2): 321-336, 2014. Disponível em <http://www.revistas2.uepg.br/index.php/emancipacao> 
consultas, o protagonismo do sujeito, o vínculo com os profissionais de saúde, os cuidados com a alimentação e a higiene, o acesso à informação, o conhecimento e a aceitação da patologia, dentre outros, contribuem para que a doença passe a ser controlável.

É importante esclarecer que a pessoa vivendo com HIV é aquela que foi infectada pelo HIV sem o surgimento de doenças oportunistas, já a com AIDS é aquela com doenças oportunistas e, consequentemente, com uso da TARV.

Desta forma, para a amostra avaliada, é possível abstrair que receber um diagnóstico positivo para o HIV, hoje, não é mais necessariamente uma sentença de morte. Inicialmente ao descobrir ser pessoa com HIVIAIDS surgem sentimentos de medo da dor e da morte, no entanto, após intervenções da equipe abordando questões psicoeducativas e adesão à TARV, há diminuição da ocorrência de infecções oportunistas, fortalecimento do sistema imunológico, meIhora da qualidade de vida e, consequentemente, entendimento e aceitação do diagnóstico, o que implica em muitos casos no aumento significativo da sobrevida.

\section{Referências}

BARKER, G. Aids e sexualidade. Disponível em: <http://www. cienciaviva. org.br/arquivo/cdebate/ artigos/aids.html> Acesso em: 03 set. 2012.

BLACK, L. W. AAIDS e o segredo. In.: E. Imber-Black (Org.). Os segredos na família e na terapia familiar. Porto Alegre: Artes Médicas; 1994.

BRASIL. Ministério da Saúde. Manual de Adesão ao tratamento para pessoas vivendo com HIV e AIDS. Brasília - DF. 2008.

BRASIL. Política Nacional de DST/AIDS: princípios e diretrizes. Coordenação Nacional de DST e AIDS. Brasília: Ministério da Saúde, 1999. Ministério da Saúde. Disponível em: <http://www.ilo.org/wcmsp5/ groups/public/---ed_protect/---protrav/- ilo_aids/ documents/legaldocument/wcms_127698.pdf $>$. Acesso em: 21 maio 2012.

BRASIL. Programa Nacional de DST e AIDS. Portal Sida. Disponível em: <http://www.portalsida. org/Organisation_Details.aspx?orgid=1428 $>$. Acesso em: 21 maio 2012.

BRASIL. A Política do Ministério da Saúde para Atenção Integral a Usuários de Álcool e outras
Drogas. 2. ed. Revista. Ampliada. Brasília: Ministério da Saúde, 2004.

BRASIL. Declaração dos Direitos Fundamentais da Pessoa Portadora do Vírus da Aids. Brasília: Ministério da Saúde, 1989.

CARACIOLO, J. M. M.; SHIMMA, E. Adesão da teoria à prática: experiências bem sucedidas no Estado de São Paulo. São Paulo. 2007.

CARACIOLO, J. M. M. et al. Manual Boas práticas de adesão HIVIAIDS. São Paulo. Bristol-Myers Squibb, 2008.

DEMO, P. Pesquisa e Informação Qualitativa: aportes metodológicos. 3. ed. Campinas: Papirus, 2006

FERNANDES, M. E. L; A pandemia da AIDS. In.: RIBEIRO, Helcion; AIDS: do preconceito à solidariedade: a partir da medicina, ciências do social e teologia. São Paulo: Paulinas, p.15, 1990.

FERREIRA, C. V. de L. AIDS e exclusão social: um estudo clínico com pacientes com o HIV. São Paulo: Lemos, 2003.

GIL, A.C. Métodos e Técnicas de pesquisa social. 6. ed. São Paulo: Atlas, 2008.

GIMENES, A. P. N. A importância da Assistência Domiciliar Terapêutica no atendimento a pacientes com AIDS. Bauru, 2002. Trabalho de Conclusão de Curso (Bacharelado em Serviço Social) - Instituição Toledo de Ensino, 2002.

HENDRICK, J. HIV: Related Losses and Grief. Halifax. Disponível em: <http://www.cpa.ca/phase>. Acesso em: 16 set. 2012.

IAMAMOTO, M.V. O serviço social na cena contemporânea. In: CONSELHO FEDERAL DE SERVIÇO SOCIAL. Serviço Social: direitos sociais e competências profissionais. Brasília: Conselho Federal de Serviço Social, 2009. P.15-50.

PARKER, R.; AGGLETON, P. Estigma, Discriminação e AIDS. Coleção ABIA. Cidadania e Direitos, $n^{\circ} 1$. Rio de Janeiro: Associação Brasileira Interdisciplinar de AIDS, 2001.

KLAFKE, T. E. O médico lidando com a morte: aspectos da relação médico - paciente terminal em cancerologia. In: CASSORLA, R. M. S. (Org.). Da morte: estudos brasileiros. Campinas: Papirus; 1991.

KUBLER-ROSS, E. Sobre a morte e o morrer. 6. ed.São Paulo: Martins Fontes, 1994. 
Mann, J. Statement at an informal briefing on AIDS to the 42nd Session of the United Nations General Assembly, 20 October, New York, 1987.

Novos números da AIDS no Brasil. Cidade. Disponível em: http://saberviver. org.br/online/publicacoes/saberviver/saber-viver-n-48/ Acesso em: 03 set. 2012.

RACHID, M.; SCHECHTER, M. Manual de HIVIAIDS. 9. Ed. Rio de Janeiro: Revinter, 2008.

SOUZA, T. R. C. Impacto Psicossocial da AIDS: enfrentando perdas; ressignificando a vida. São Paulo: Centro de Referência e Treinamento DST/AIDS, 2008. São Paulo. Série: Prevenção as DST/AIDS.

STEDEFORD, A. Encarando a morte: uma abordagem ao relacionamento com o paciente terminal. Tradução S. Ribeiro. Porto Alegre: Artes Médicas, 1986. 